\title{
Enhanced biohydrogen production from cotton stalk hydrolysate of Enterobacter cloacae WL1318 by overexpression of the formate hydrogen lyase activator gene
}

Qin Zhang ( $\nabla$ jhtabszq@163.com )

Anhui Polytechnic University

Shaolin You

Anhui Polytechnic University

Yanbin Li

Anhui Polytechnic University

Xiaowei Qu

Tarim University

Hui Jiang

Tarim University

\section{Research}

Keywords: Biohydrogen production, Formate hydrogen lyase activator gene, Overexpression, Cotton stalk hydrolysate, Recombinant strain

Posted Date: February 20th, 2020

DOI: https://doi.org/10.21203/rs.2.24105/v1

License: (c) (1) This work is licensed under a Creative Commons Attribution 4.0 International License.

Read Full License

Version of Record: A version of this preprint was published at Biotechnology for Biofuels on May 22nd, 2020. See the published version at https://doi.org/10.1186/s13068-020-01733-9. 


\section{Abstract}

Background Biohydrogen production from lignocellulose has become an important hydrogen production method due to its diversity, renewability, and cheapness. Overexpression of the formate hydrogen lyase activator ( fhlA) gene is a promising tactic for enhancement of hydrogen production in facultative anaerobic Enterobacter . However, little work has been reported in terms of the fhlA gene cloning and expression in Enterobacter cloacae as well as the engineered strain for lignocellulose-based hydrogen production.

Results The formate hydrogen lyase activator ( fhIA ) gene was cloned and overexpressed in Enterobacter cloacae WL1318, and the cumulative hydrogen production and dynamics, glucose and xylose consumption, cell growth, and soluble metabolites were analyzed in the wild and recombinant strains. The results showed that the recombinant strain significantly enhanced cumulative hydrogen production by $188 \%$ following fermentation of cotton stalk hydrolysate for $24 \mathrm{~h}$, and maintained improved production above $30 \%$ throughout the fermentation process compared to the wild strain. Accordingly, overexpression of the fhIA gene resulted in an enhanced hydrogen production potential $(P)$ and maximum hydrogen production rate $(R \mathrm{~m})$, as well as a shortened lag phase time $(\lambda)$ for the recombinant strain. Additionally, the recombinant strain also displayed improved glucose (12\%) and xylose (3.4\%) consumption and hydrogen yield $\mathrm{Y}(\mathrm{H} 2 / \mathrm{S})(37.0 \%)$ compared to the wild strain. Moreover, the metabolites and specific enzyme profiles demonstrated that reduced flux in the competitive branch, including succinic, acetic, and lactic acids, and ethanol generation, coupled with increased flux in the pyruvate node and formate splitting branch, benefited hydrogen synthesis.

Conclusions The results conclusively prove that overexpression of fhIA gene in E. cloacae WL1318 can effectively enhance the hydrogen production from cotton stalk hydrolysate, and reduce the metabolic flux in the competitive branch. It's the first attempt to engineer the fhIA gene in the hydrogen producing bacterium E. cloacae. This work provides a highly efficient engineered bacterium for biohydrogen production from fermentation of lignocellulosic hydrolysate in the future.

\section{Background}

With the worsening energy crisis and exhaustion of traditional fossil energy dominated by petroleum, energy production based on lignocellulose bioconversion has attracted worldwide attention [1-5]. Hydrogen is the cleanest energy on earth, and has become the most competitively exploited renewable form of energy in the world [6-9]. In recent years, biohydrogen production from lignocellulose has become an important hydrogen production method due to its diversity, renewability, and cheapness [1013].

During the dark fermentation stage of lignocellulosic hydrogen production, fermentative microorganisms play an important role, and engineering the alteration of key enzyme genes in the hydrogen generation pathway has become an important way of improving the hydrogen production potential of hydrogen- 
producing strains [14-16]. Metabolic pathways for microbial hydrogen synthesis vary with microbial species, but can be classified into three types: (1) the mixed acid fermentation pathway of facultative anaerobes represented by Enterobacter (hydrogen production via formate hydrogen lytic reaction); (2) the butyric acid fermentation pathway of obligate anaerobic bacteria represented by Clostridium (hydrogen production catalyzed by pyruvate:ferredoxin oxidoreductase); and (3) the NADH regeneration pathway [17-19]. Amongst these, the mixed acid fermentation pathway, which is mainly catalyzed by the formate hydrogen lyase $(\mathrm{FHL})$, is the most studied and widely used for hydrogen production $[20,21]$. The $\mathrm{FHL}$ complex exists in various microbial genera, especially E. coli, which has been the most extensively characterized at both the physiological and genetic levels. Nevertheless, research on the FHL complex in other species of the Enterobacter genus is still limited; only a few studies have reported fhlA gene expression in Enterobacter aerogenes [22], Enterobacter sp. CN1 [23] and Klebsiella HQ-3 [24], whereas the fhIA gene of Enterobacter cloacae and its expression have not yet been reported.

In recent years, great efforts have been made in metabolic engineering to improve the hydrogen production potential of hydrogen-producing bacteria. However, most of the engineered hydrogenproducing bacteria reported can only utilize single carbon sources, like glucose, for hydrogen production [25-27]. Studies involving engineered bacteria utilizing lignocellulose and its hydrolysates for hydrogen production are few, as most focus on the simultaneous saccharification and fermentation (SSF) of cellulose and xylose utilization; for example, an L-lactate dehydrogenase gene (Idh) deletion in Caldicellulosiruptor bescii increased acetate and $\mathrm{H}_{2}$ production by $21-34 \%$ relative to the wild type [28], and the overexpression of xylulokinase and xylose isomerase in Klebsiella oxytoca HP1 increased hydrogen yield by $33.04 \%$ and $41.31 \%$, respectively, relative to the wild type [29]. A hydrogen-producing bacterium Enterobacter cloacae WL1318, which has been reported to utilize cotton stalk hydrolysate for hydrogen production [30], was obtained by our group. Based on the strain's intrinsic sugar utilization and hydrogen production properties, the xylose metabolic pathway of Enterobacter cloacae WL1318 does not require modification for lignocellulose-based hydrogen production, but requires specific engineering of its biohydrogen synthesis pathway for enhancement of hydrogen production. However, studies regarding this and the cloning and expression of FHL-related genes in E. cloacae are currently limited; only studies on [Fe] hydrogenase gene cloning and expression have been reported [31-33].

In this study, in order to understand the regulation of the formate hydrogen lytic pathway for hydrogen production in E. cloacae WL1318 and improve its hydrogen production potential using cotton stalk hydrolysate as the fermentative substrate, we cloned an FHL activator gene (fhlA) from the wild $\mathrm{E}$. cloacae WL1318 to achieve homologous overexpression of fhIA. Moreover, the cumulative hydrogen production and dynamics, glucose and xylose consumption, cell growth, and soluble metabolites were analyzed in both the wild type and recombinant E. cloacae WL1318.

\section{Results And Discussion}

Cloning, analysis and overexpression of the fhIA gene in E. cloacae WL1318 
The full-length sequence of fhIA (2058 bp) was successfully cloned using the primer pair, fhlA-fw and fhIA-rv, which encoded a peptide of 685 amino acids with a calculated molecular mass of $\sim 77 \mathrm{kDa}$ and a predicted pl of 5.78. The gene sequence has been deposited in the GenBank database under the accession number, MN549464. The results from a BlastP search using the amino acid sequence encoded by fhIA to query the GenBank database showed that the peptide was $>95 \%$ homologous with peptides from different species within the genus, Enterobacter. The phylogenetic tree (Fig. 1) showed that the formate hydrogen lyase transcriptional activator (FHLA) protein of E. cloacae WL1318 is located in the same branch with Enterobacter sp. (WP_148576644.1), indicating the closest relationship between both proteins. Qiu et al. (2014) cloned an fhIA gene from Enterobacter sp. CN1, whose amino acid sequences showed highest similarity with that of E. cloacae subsp. cloacae NCTC9493 [23]. Such phenomenon revealed that FHLA may exhibit high similarity among different species of Enterobacter, other than limited to the same species.

fhlA was subcloned using the primer pair, PfhlA-fw and PfhlA-rv, into pET28a, and this clone was transformed into E. cloacae WL1318. The His-FHLA fusion protein expression was evaluated via SDSPAGE, which showed that the fusion protein had a molecular weight of $77 \sim 78 \mathrm{kDa}$, consistent with the size of the His-tag $(0.6 \mathrm{kDa})$ and the predicted FHLA of $77 \mathrm{kDa}$ (Fig. 2b). The expression of the fhlA gene in the recombinant strain was estimated via western blotting, and the level of the encoded protein was observed to be markedly increased (Fig. 2a).

\section{Enhanced hydrogen production via fhlA gene overexpression}

The time course profiles for cumulative hydrogen production for wild and recombinant strains are shown in Fig. 3. The histogram shows that the hydrogen production of the recombinant strain at each fermentation time point was higher than that of the wild strain, and production was particularly enhanced by up to $~ 188 \%$ after $24 \mathrm{~h}$ fermentation, compared with the wild strain. This indicated that the recombinant strain had a higher hydrogen production potential with fhIA overexpression, thereby generating hydrogen gas rapidly and in large quantity during the early fermentation stage (within $24 \mathrm{~h}$ ). Therefore, the homologous expression of fhIA in E. cloacae WL1318 significantly enhanced fhIA expression in the early fermentation stage. The improvement in cumulative hydrogen production was maintained at $>30 \%$ (up to $38.5 \%$ ) throughout the fermentation period (up to $120 \mathrm{~h}$ ), indicating that the recombinant strain can also maintain high hydrogen production efficiency during the fermentation process.

Cumulative hydrogen production by the wild and recombinant strains were dynamically fitted by the Gompertz model, and the calculated parameters and correlation coefficients are listed in Table 1. Correlation coefficients with $\mathrm{R}^{2}$ values higher than 0.98 , indicate a good correlation between the experimental data and the model in both the wild and recombinant strains. By comparison, it was discovered that the $\mathrm{P}$ and $\mathrm{R}_{\mathrm{m}}$ of the recombinant strain were significantly higher than those of the wild 
strain (Table 1), suggesting that the strain's $P$ and $R_{m}$ can be significantly enhanced via fhlA overexpression. Additionally, the lag phase time $(\lambda)$ of the recombinant strain was shortened to $2.91 \mathrm{~h}$, which was much shorter than that of the wild type (Table 1), indicating that fhlA overexpression shortened the adaptive time and accelerated the fermentative hydrogen production process of the recombinant strain.

The main reducing sugars in cotton stalk hydrolysate are glucose and xylose as previously reported [34, 35]. The wild E. cloacae WL1318 could utilize both glucose and xylose in cotton stalk hydrolysate, and we found that the insertion of the fhIA gene did not change its sugar utilization properties, but enhanced glucose and xylose consumption by $12.0 \%$ and $3.4 \%$, respectively (Table 2 ). Correspondingly, the hydrogen yield $\mathrm{Y}\left(\mathrm{H}_{2} / \mathrm{S}\right)$ of the recombinant strain increased by $37.0 \%$ compared to the wild strain (Table 2). The results indicated that the fhIA gene insertion enhanced hydrogen generation, as well as reducing sugar consumption, resulting in an improved hydrogen yield. On the other hand, there was no

obvious difference in $\triangle \mathrm{OD}_{600}$ between the wild and recombinant strains, suggesting that the recombinant strain could maintain a similar growth rate as the wild strain.

\section{Redistribution of metabolic flux influenced by fhIA gene overexpression}

Through metabolic flux analysis based on quasi-steady state, Qu (2018) proposed the metabolic pathway of E. cloacae WL1318 for hydrogen production from fermentation of cotton stalk hydrolysate as follows: glucose and xylose are metabolized via the Embden-Meyerhof-Parnas and Pentose Phosphate Pathways, and further converted to pyruvate [36]. Based on the central anaerobic metabolism of Enterobacter, pyruvate is split into formate and acetyl-CoA by pyruvate formate lyase; $\mathrm{H}_{2}$ and $\mathrm{CO}_{2}$ are then produced from formate catalyzed by FHL via the mixed acid fermentation pathway (Fig. 4) [37, 38]. Metabolites, such as lactate, formate, ethanol, acetate, and succinate, are also produced in this pathway, hence, we measured these metabolites and pyruvate in both the wild and recombinant strains.

After glucose and xylose transporting, most of the carbons were directed to pyruvic acid. Pyruvic acid is the key node compound, which starts the mixed acid fermentation. Significant increases in pyruvic acid during the fermentation stage were detected in the recombinant strain. Compared with the wild strain, pyruvic acid concentration was maintained at $>100 \mathrm{mg} / \mathrm{L}$ over a $120 \mathrm{~h}$ fermentation period. It may be inferred that the fhIA gene insertion increased carbon flux to the pyruvic acid node, which further influenced the flux distribution of the mixed acid fermentation pathway. Succinic acid in the recombinant strain accumulated in the early stage of fermentation with a higher concentration than in the wild strain, but this concentration dropped sharply in the mid to late fermentation stage, indicating that succinic acid only competed for carbon flux at the early fermentation stage. Ethanol accumulated at the late fermentation stage in the wild strain, but the concentration decreased slightly in the recombinant strain. Acetic and lactic acid concentrations peaked at the mid-fermentation stage in the recombinant strain, similar to those in the wild strain. Contrastingly, acetic and lactic acid concentrations were lower at most 
time points during the fermentation stage than in the wild strain, illustrating a reduced flux flow in the competitive branch of hydrogen synthesis in the recombinant strain. Formic acid splitting directly leads to biohydrogen generation in the recombinant strain. Figure 4 shows that the concentrations of residue formic acid were higher during the fermentation stage in the recombinant strain than in the wild strain except at $48 \mathrm{~h}$, indicating the enhancement of carbon flux in the hydrogen generation branch. We think that the increased carbon flux promoted biohydrogen production and maintained more residue formic acid, which might further increase biohydrogen production.

Formate hydrogen lyase ( $\mathrm{FHL}$ ) directly catalyzes the splitting of formic acid into $\mathrm{H}_{2}$ and $\mathrm{CO}_{2}$. During the hydrogen production process, the $\mathrm{FHL}$ activity increased significantly in the recombinant strain from fermenting $24 \mathrm{~h}$ to $72 \mathrm{~h}$, and obtained the highest enhancement of about $21 \%$ compared to the wild strain (Fig. 5a). This indicated that high FHL activity led to the conversion of formic acid to large amounts to hydrogen gas from the early to the mid stage.

Lactate dehydrogenase (LDH) is a rate-limiting enzyme that catalyzes the conversion of pyruvate to lactic acid, which may decrease the metabolic flux to hydrogen synthesis. The LDH activities varied in a similar trend in the wild and recombinant strains, and both obtained the peak values at the mid fermentation stage (Fig. 5b), which was also similar to the variation in lactic acid concentration (Fig. 4). Overall, the activities of the recombinant strain were lower than those of the wild strain during the entire fermentation stage (Fig. 5B). Aldehyde dehydrogenase (ALDH) catalyzes the conversion of acetyl-CoA to ethanol and acetic acid and its activities significantly decreased after 48 to $120 \mathrm{~h}$ fermentation in the recombinant strain compared to the wild strain (Fig. 5c), indicating that fhlA overexpression could decrease the metabolic flux of this branch, which is beneficial for more metabolic flux flow to the biohydrogen synthesis pathway.

\section{Conclusions}

Overexpression of fhIA gene is a promising tactic for enhancing hydrogen production in facultative anaerobic Enterobacter. In this study, fhIA gene was effectively cloned and overexpressed in E. cloacae WL1318. Compared to the wild strain, the recombinant strain significantly enhanced hydrogen production from the fermentation of cotton hydrolysate for $24 \mathrm{~h}$ by $~ 188 \%$, and maintained $>30 \%$ improved production throughout the fermentation stage. Additionally, the recombinant strain also displayed enhanced $P$ and $R_{m}$, shortened lag phase time, and improved reducing sugar consumption and hydrogen yield $\mathrm{Y}\left(\mathrm{H}_{2} / \mathrm{S}\right)$ compared to the wild strain. Moreover, the metabolite profile demonstrated that flux reduction in the competitive branch, including succinic, acetic, and lactic acids, and ethanol generation, and increases in flux in the pyruvate node and formate splitting branch benefited hydrogen synthesis. These trends were confirmed by activity assays of the enzymes, FHL, LDH, and ALDH.

\section{Methods}


Strains and plasmids used in this study are provided in Table 3. E. cloacae WL1318, a bacterium reported to utilize cotton stalk hydrolysate for hydrogen production [30], served as the wild type strain from which recombinants were constructed. A previously described [30] growth medium was used for the wild strain; glucose $10 \mathrm{~g} / \mathrm{L}$, xylose $10 \mathrm{~g} / \mathrm{L}$, beef extract $5 \mathrm{~g} / \mathrm{L}$, peptone $10 \mathrm{~g} / \mathrm{L}, \mathrm{NaCl} 5 \mathrm{~g} / \mathrm{L}, \mathrm{KH}_{2} \mathrm{PO}_{4} 0.5 \mathrm{~g} / \mathrm{L}$, and $\mathrm{MgSO}_{4} \cdot 7 \mathrm{H}_{2} \mathrm{O} 0.5 \mathrm{~g} / \mathrm{L}$. E. coli DH5a served as the host strain for plasmid construction. Recombinant strain E. cloacae WL1318 - fhIA and E. coli DH5a were grown in LB medium and the antibiotics, $50 \mu \mathrm{g} / \mathrm{mL}$ ampicillin and $10 \mu \mathrm{g} / \mathrm{mL}$ kanamycin, were prepared and added into the media when required.

\section{Preparation of cotton stalk hydrolysate}

Cotton stalks were harvested from a cotton field in Xinjiang Alaer, China, dried, milled and sifted to 20mesh size before being hydrolyzed. The fermentable sugar solution of the cotton stalk hydrolysate was prepared following optimum hydrolysis, then detoxified and decolorized as previously described [34, 35 ,

39]. The main sugar components in the hydrolysate solution were glucose and xylose [35,40], which were modified to a previously determined optimum concentration and used as the substrate medium in the following fermentation experiments.

\section{Cloning of the fhIA gene in Enterobacter cloacae WL1318 and sequence analysis}

The total DNA of E. cloacae WL1318 was extracted using an Ezup Column Bacterial Genomic DNA Purification Kit (Sangon, Shanghai, China). Strains and plasmids used in this study were listed in Table 3. The sequence of the E. cloacae WL1318 fhIA gene was obtained via PCR (polymerase chain reaction) using the primer pair, fhlA-fw and fhlA-rv (Table 4), which was designed based on the open reading frames (ORF) of FHLA proteins from related facultative anaerobic bacteria. Related DNA and protein sequences were retrieved using the BLAST program in the NCBI database, multiple sequence alignments of amino acid sequences were performed using ClustalW program, and a phylogenetic tree was constructed via the MEGA 6.0 software using the neighbor-joining algorithm with a bootstrap support value of 1,000 replicates.

\section{Sub-cloning and overexpression of the fhIA gene in Enterobacter cloacae WL1318}

The gene fhIA was purified, and sub-cloned via PCR amplification using the primers, PfhlA-fw and PfhlArv, containing EcoR I and Xho I sites (underlined), respectively. The PCR product was purified and ligated to the pUCm-T vector, the purified plasmid, pUCm-T-fhIA, was digested with EcoR I and Xho I, and inserted into the multiple cloning site of the prokaryotic expression vector, pET28a, forming the recombinant plasmid, pET28a-fhIA (Kan'). The recombinant plasmid with the fhIA insert was purified and confirmed by double enzyme digestion and sequencing, then transformed into the E. cloacae WL1318 competent cells by electroporation ( $2500 \mathrm{~V}, 200 \Omega, 25 \mu \mathrm{F}$ ) to obtain the recombinant strain E. cloacae WL1318- fhlA.

Cells of the recombinant strain were induced with $1 \mathrm{mmol} / \mathrm{L}$ IPTG for $6 \mathrm{~h}$, harvested, and lysed using an ultrasonic cell disruptor ( $3 \mathrm{~s}, 1 \mathrm{~s}, 15 \mathrm{~min}$ ) (Scientz-IID, SCIENTZ, Ningbo, China). Proteins were collected by centrifugation, and analyzed via $12 \%$ sodium dodecyl sulfate polyacrylamide gel electrophoresis (SDS- 
PAGE) to primarily confirm FHLA protein expression. Western blots were performed via the Novel One Step Western Blot Kit I (Sangon, Shanghai, China) and the specific fhIA encoded protein was examined using the W-TMB chromogenic kit (Sangon, Shanghai, China).

\section{Batch fermentation for biohydrogen production}

Single colonies of the recombinant strain E. cloacae WL1318 - fhIA were selected and inoculated in $3 \mathrm{~mL}$ LB medium (including $10 \mu \mathrm{g} / \mathrm{mL}$ kanamycin) and cultured overnight at $37^{\circ} \mathrm{C}, 180 \mathrm{r} / \mathrm{min}$, then 3-mL broth was inoculated with $30 \mathrm{~mL}$ fresh seed medium (glucose $10 \mathrm{~g} / \mathrm{L}$, xylose $10 \mathrm{~g} / \mathrm{L}$, beef extract $5 \mathrm{~g} / \mathrm{L}, \mathrm{NaCl}$ $5 \mathrm{~g} / \mathrm{L}$, peptone $10 \mathrm{~g} / \mathrm{L}, \mathrm{KH}_{2} \mathrm{PO}_{4} 0.5 \mathrm{~g} / \mathrm{L}, \mathrm{MgSO}_{4} \cdot 7 \mathrm{H}_{2} \mathrm{O} 0.5 \mathrm{~g} / \mathrm{L}$, and $10 \mu \mathrm{g} / \mathrm{mL}$ kanamycin), which was then shake-cultivated at $37{ }^{\circ} \mathrm{C}$ and $180 \mathrm{r} / \mathrm{min}$ until the optical density value at $600 \mathrm{~nm}\left(\mathrm{OD}_{600}\right)$ reached $0.4 \sim$ 0.6 (after $2 \sim 3 \mathrm{~h}$ ). Next, sterilized IPTG was added to a final concentration of $1 \mathrm{mmol} / \mathrm{L}$ to induce expression at $37^{\circ} \mathrm{C}$ for $6 \mathrm{~h}$. The entire $30 \mathrm{~mL}$ seed broth was introduced into the fermentation medium composed of the following: cotton stalk hydrolysate (reducing sugar concentration $40 \mathrm{~g} / \mathrm{L}$ ) $1000 \mathrm{~mL}$, beef extract $5 \mathrm{~g} / \mathrm{L}$, peptone $10 \mathrm{~g} / \mathrm{L}, \mathrm{NaCl} 5 \mathrm{~g} / \mathrm{L}, \mathrm{KH}_{2} \mathrm{PO}_{4} 0.5 \mathrm{~g} / \mathrm{L}, \mathrm{MgSO}_{4} \cdot 7 \mathrm{H}_{2} \mathrm{O} 0.5 \mathrm{~g} / \mathrm{L}$, kanamycin $10 \mu \mathrm{g} / \mathrm{mL}$, and IPTG at a final concentration of $1 \mathrm{mmol} / \mathrm{L}$. The fermenter was well sealed to maintain anaerobic conditions for hydrogen production and cultivation was performed at $37^{\circ} \mathrm{C}$ for $120 \mathrm{~h}$. The fermentation method for hydrogen production was also applied to the wild strain without the addition of kanamycin and IPTG. All the experiments were carried out in triplicates. The volume of the fermentative hydrogen was examined thrice every $24 \mathrm{~h}$ and summed to obtain the daily hydrogen production, which was measured at each fermentation time point, was accumulated and calculated as the cumulative hydrogen production in the corresponding fermentation period. The concentration of the main soluble metabolites, glucose, and xylose in the cotton stalk hydrolysate were measured at 24-h intervals.

\section{Analytical methods and calculations}

The hydrogen gas volume was measured via $1 \mathrm{~mol} / \mathrm{L} \mathrm{NaOH}$ displacement in an inverted burette, and the gas concentration was examined using a hand-held hydrogen detector (KP810H20, Henan Zhong'an Electronic Detection Technology Co Ltd, Zhengzhou, China). At each sampling time, bacterial growth was measured via the $\mathrm{OD}_{600}$ using a UV-visible spectrophotometer (7230G, Jinghua Instruments Co. Ltd., Shanghai, China). The rest of the aqueous samples were centrifuged at $8000 \times \mathrm{g}$ for $10 \mathrm{~min}$ and filtered through syringe filters with $0.22 \mu \mathrm{m}$ membranes before analysis. The total concentration of reducing sugars in the broth was determined via the 3,5-dinitryl-salicylic acid reagent (DNS) method [41]. Glucose concentration was measured using a glucose detection kit (Comin Biotechnology, Suzhou, China) via the principle of glucose oxidation and colorimetry, using a UV-visible spectrophotometer (7230G, Jinghua Instruments Co Ltd, Shanghai, China). Xylose concentration was measured using a xylose detection kit (ZZStandard, Shanghai, China) via the xylose dehydrogenation reaction and detection of NADH formation using a UV-visible spectrophotometer (7230G, Jinghua Instruments Co. Ltd., Shanghai, China). The concentrations of soluble metabolites, such as succinate, lactate, acetate, pyruvate, formate and ethanol were measured using detection kits (ZZStandard, Shanghai, China) according to the manufacturers' instructions. 
The reducing sugar (glucose or xylose) consumption $(\%, w / w)$ in the cotton stalk hydrolysate was calculated as a percentage of the initial sugar concentration in the fermentative medium. The difference between the $\mathrm{OD}_{600}$ value in the final fermentation broth $(120 \mathrm{~h})$ and that in the initial fermentation broth $(\mathrm{O} h)$ was described as the increment in $\mathrm{OD}_{600}\left(\Delta \mathrm{OD}_{600}\right)$. The hydrogen yield $\mathrm{Y}\left(\mathrm{H}_{2} / \mathrm{S}\right)\left(\mathrm{mol} \mathrm{H}_{2} / \mathrm{mol}\right.$ sugar $)$ was defined as hydrogen concentration generated from the consumed reducing sugar in the cotton stalk hydrolysate.

The kinetic parameters of the cumulative hydrogen production in batch fermentation experiments were calculated using the modified Gompertz model (Eq. 1) [42] as follows:

$$
H=P \times \exp \left\{-\exp \left[\frac{R_{m} \times e}{P}(\lambda-t)+1\right]\right\}
$$

(Eq. 1)

Where $\mathrm{H}$ is the cumulative hydrogen production $(\mathrm{mL} / \mathrm{L}), \mathrm{P}$ is the hydrogen potential $(\mathrm{mL} / \mathrm{L}), R_{m}$ is the maximum hydrogen production rate $(\mathrm{mL} /(\mathrm{L} \cdot \mathrm{h}))$, e is $2.71828, \lambda$ is the lag phase time $(h)$, and $t$ is the culture time (h). The kinetic parameters $\left(P, R_{m}\right.$, and $\left.\lambda\right)$ were estimated via Sigmaplot software 12 .

\section{Assay of FHL activity and specific related metabolic enzyme activity}

FHL activity was assayed as described by Yoshida et al. (2005) [21]. The specific hydrogen production rate was measured as the rate of hydrogen produced at $37^{\circ} \mathrm{C}$ from a stirred cell suspension at an $\mathrm{OD}_{600}$ of 1.0 in $50 \mathrm{~mL}$ PBS in the presence of $100 \mathrm{mmol} / \mathrm{L}$ sodium formate. The volumetric hydrogen production rate was measured at $37^{\circ} \mathrm{C}$ by injecting $25 \mathrm{mmol} / \mathrm{L}$ formic acid into $100 \mathrm{~mL}$ cell suspension in a mixing reactor. The hydrogen concentration was examined using a hand-held hydrogen detector $(\mathrm{KP} 810 \mathrm{H} 20$; Henan Zhong'an Electronic Detection Technology Co Ltd, Zhengzhou, China).

LDH activity was examined using an LDH kit (Comin, Suzhou, China) based on the principle of lactic acid oxidation and colorimetry. ALDH activity was determined using an ALDH kit (Comin, Suzhou, China) based on the principle of aldehyde oxidation and colorimetry.

\section{Abbreviations}

FHL: formate hydrogen lyase; FHLA: formate hydrogen lyase activator; ORF: open reading frame; SDSPAGE: sodium dodecyl sulfate polyacrylamide gel electrophoresis; G6P: glucose-6-phosphate; G6PA: glucose-6-phosphate acid; X5P: xylulose 5-phosphate; G3P: 3-phosphoglyceric acid; LDH: lactate dehydrogenase; ALDH: aldehyde dehydrogenase; PBS: phosphate buffered solution; DNS: 3,5-dinitrylsalicylic acid reagent.

\section{Declarations}

\section{Acknowledgments}


Not applicable.

\section{Authors' contributions}

QZ designed the experiments, handled the data and drafted the manuscript. SLY and XWQ performed the fhIA gene expression experiments. YBL and $\mathrm{HJ}$ carried out the fermentation experiments and examined the key metabolites and enzyme activities. All authors read and approved the final manuscript.

\section{Funding}

This work was financially supported by the National Natural Science Foundation of China (21406150), the Key Research and Development Project of Anhui Province in China (201904a07020003), and the Talent Start-up Fund of Anhui Polytechnic University in China (2018YQQ029).

\section{Availability of data and materials}

All data generated or analysed during this study are included in this published article and its additional files.

\section{Ethics approval and consent to participate}

Not applicable.

\section{Consent for publication}

Not applicable.

\section{Competing interests}

The authors declare that they have no competing interests.

\section{Additional File}

Additional file: Fig. S1. Nucleotide sequence of the formate hydrogen lyase activator ( $f h / A)$ gene of $E$. cloacae WL1318; Fig. S2. Amino acid sequence of the formate hydrogen lyase activator (FHLA) of $E$. cloacae WL1318; Fig. S3. Reference amino acid sequences of FHLA in related genera of Enterobacterfor construction of the phylogenetic tree.

\section{References}

1. Rodionova MV, Poudyal RS, Tiwari I, Voloshin RA, Zharmukhamedov SK, Nam HG, Zayadan BK, Bruce BD, Hou HJM, Allakhverdiev SI. Biofuel production: challenges and opportunities. Int J Hydrogen Energy. 2017; 42: 8450-8461.

2. Saratale GD, Oh MK. Improving alkaline pretreatment method for preparation of whole rice waste biomass feedstock and bioethanol production. RSC Adv. 2015; 5: 91171-91179. 
3. Liu W, Wang Y, Yu Z, Bao J. Simultaneous saccharification and microbial lipid fermentation of corn stover by oleaginous yeast Trichosporon cutaneum. Bioresour Technol. 2012; 118: 13-18.

4. Taherdanak M, Zilouei $\mathrm{H}$, Improving biogas production from wheat plant using alkaline pretreatment. Fuel. 2014; 115: 714-719.

5. Liang YN, Tang TY, Umagiliyage AL, Siddaramu T, McCarroll M, Choudhary R. Utilization of sorghum bagasse hydrolysates for producing microbial lipids. Appl Energ. 2012; 91: $451-458$.

6. Boodhun BSF, Mudhoo A, Kumar G, Kim SH, Lin CY. Research perspectives on constraints, prospects and opportunities in biohydrogen production. Int J Hydrogen Energy. 2017; 42: 27471-81.

7. Sivagurunathan P, Kumar G, Mudhoo A, Rene ER, Saratale GD, Kobayashi T, Xu K, Kim SH, Kim DH. Fermentative hydrogen production using biomass: an overview of pretreatment methods, inhibitor effects and detoxification experiences. Renew Sustain Energy Rev. 2017; 77: 28-42.

8. Wang J, Yin Y. Fermentative hydrogen production using various biomass-based materials as feedstock. Renew Sustain Energy Rev. 2018; 92:284-306.

9. Kamaraj M, Ramachandran KK, Aravind J. Biohydrogen production from waste materials: benefts and challenges. Int J Environ Sci Technol. 2020; 17: 559-576.

10. Zilouei $\mathrm{H}$, Taherdanak M. Biohydrogen from Lignocellulosic wastes. In: Karimi, K. (Ed.), Lignocellulose-Based Bioproducts. Springer International Publishing, Switzerland, 2015; Chapter7: 253-288.

11. Rezania S, Din MFD, Tai SM, Sohaili J, Chelliapan S, Kamyab H, Saha BB. Review on fermentative biohydrogen production from water hyacinth, wheat straw and rice straw with focus on recent perspectives. Int J Hydrogen Energy. 2017; 42: 20955-

12. Hosseini SE, Wahid MA. Hydrogen production from renewable and sustainable energy resources: promising green energy carrier for clean development. Renew Sustain Energy Rev. 2016; 57: 850-66.

13. Asadi N, Zilouei $\mathrm{H}$. Optimization of organosolv pretreatment of rice straw for enhanced biohydrogen production using Enterobacter aerogenes. Bioresour Technol. 2017; 227: 335-344.

14. Soo CS, Yap WS, Hon WM, Ramli N, Shah UKM, Phang LY. Improvement of hydrogen yield of ethanolproducing Escherichia coli recombinants in acidic conditions. Electron J Biotechn. 2017; 26: 27-32.

15. Lu Y, Zhao H, Zhang C, Xing XH. Insights into the global regulation of anaerobic metabolism for improved biohydrogen production. Bioresour Technol. 2016; 200: 35-41.

16. Zhao H, Lu Y, Wang L, Zhang C, Yang C, Xing X. Disruption of lactate dehydrogenase and alcohol dehydrogenase for increased hydrogen production and its effect on metabolic flux in Enterobacter aerogenes. Bioresour Technol. 2015; 194: 99-107.

17. Oh YK, Raj SM, Jung GY, Park S. Current status of the metabolic engineering of microorganisms for biohydrogen production. Bioresour Technol. 2011; 102: 8357-8367.

18. Cabrol L, Marone A, Tapia-Venegas E, Steyer JP, Ruiz-Filippi G, Trably E. Microbial ecology of fermentative hydrogen producing bioprocesses: useful insights for driving the ecosystem function. FEMS Microbiol Rev. 2017; 43(41): 158-181. 
19. Mohanraj S, Pandey A, Mohan SV, Anbalagan K, Kodhaiyolii S, Pugalenthi V. Metabolic engineering and molecular biotechnology of biohydrogen production [M]. Biohydrogen. 2019; Chapter 17: 413434.

20. Zhao HX, Ma K, Lu Y, Zhang C, Wang LY, Xing XH. Cloning and knockout of formate hydrogenlyase and $\mathrm{H}_{2}$-uptake hydrogenase genes in Enterobacter aerogenes for enhanced hydrogen production. Int J Hydrogen Energy. 2009; 34: 186-194.

21. Yoshida A, Nishimura T, Kawaguchi H, Inui M, Yukaw $H$. Enhanced hydrogen production from formic acid by formate hydrogen lyase-overexpressing Escherichia coli Appl Environ Microb. 2005; 71(11): 6762-6768.

22. Lu Y, Zhao H, Zhang C, Lai Q, Xing XH. Perturbation of formate pathway for hydrogen production by expressions of formate hydrogen lyase and its transcriptional activator in wild Enterobacter aerogenes and its mutants. Int J Hydrogen Energy. 2009; 34: 5072 - 5079.

23. Qiu Y, Huang J, Nian D, Zhang M, Long M, Hu Z. Increased formate-dependent $\mathrm{H}_{2}$ production from xylose in Enterobacter CN1 transformed with a formate hydrogenlyase activator gene. J Renew Sustain Energy. 2014; 6: 053136.

24. Jawed M, Pi J, Xu L, Zhang $H$, Hakeem A, Yan Y. Enhanced $\mathrm{H}_{2}$ production and redirected metabolic flux via overexpression of fhlA and $p n c B$ in Klebsiella HQ-3 strain. Appl Biochem Biotech. 2015; 178(6): 1113-1128.

25. Kim S, Seol E, Oh YK, Wang GY, Park S. Hydrogen production and metabolic flux analysis of metabolically engineered Escherichia coli Int J Hydrogen Energy. 2009; 34: 7417-7427.

26. Maeda T, Sanchez-Torres V, Wood TK. Enhanced hydrogen production from glucose by metabolically engineered Escherichia coli. Appl Microbiol Biotechnol. 2007; 77: 879-890.

27. Zhou P, Wang Y, Gao R, Tong J, Yang Z. Transferring [NiFe] hydrogenase gene from Rhodopeseudomonas palustris into coli BL21(DE3) for improving hydrogen production. Int J Hydrogen Energy. 2015; 40: 4329-4336.

28. Cha M, Chung D, Elkins JG, Guss AM, Westpheling J. Metabolic engineering of Caldicellulosiruptor bescii yields increased hydrogen production from lignocellulosic biomass. Biotechnol Biofuels. 2013; 6: 85-91.

29. Wu XB, Huang GF, Bai LP, Long MN, Chen QX. Enhanced hydrogen production from xylose and bamboo stalk hydrolysate by overexpression of xylulokinase and xylose isomerase in Klebsiella oxytoca Int J Hydrogen Energy. 2014; 39: 221-230.

30. Qu XW, Li YB, Zhang Q. Effect of subsection control of $\mathrm{pH}$ value on hydrogen production from fermentation of cotton stalk hydrolysate by Enterobacter cloacae China Brewing. 2018; 37(5): 157161. (in Chinese)

31. Mishra J, Kumar N, Ghosh AK, Das D. Isolation and molecular characterization of hydrogenase gene from a high rate of hydrogen-producing bacterial strain Enterobacter cloacae IIT-BT 08. Int J Hydrogen Energy. 2002; 27: 1475-1479. 
32. Mishra J, Khurana S, Kumar N, Ghosh AK, Das D. Molecular cloning, characterization, and overexpression of a novel [Fe]-hydrogenase isolated from a high rate of hydrogen producing Enterobacter cloacae IIT-BT 08. Biochem Bioph Res Co. 2004; 324: 679-685.

33. Dutta T, Das AK, Das D. Purification and characterization of [Fe]-hydrogenase from high yielding hydrogen-producing strain, Enterobacter cloacae IIT-BT08 (MTCC5373). Int J Hydrogen Energy. 2009; 34: 7530-75377.

34. Zhang Q, Li Y, Xia L, Liu Z, Pu Y. Enhanced xylitol production from statistically optimized fermentation of cotton stalk hydrolysate by immobilized Candida tropicalis. Chem Biochem Eng Q. 2014; 28: 13-

35. Zhang Q, Li YB, Xia LM. An oleaginous endophyte Bacillus subtilisHB1310 isolated from thin-shelled walnut and its utilization of cotton stalk hydrolysate for lipid production. Biotechnol Biofuels. 2014; 7: $152-$

36. Qu XW. Regulation of hydrogen production from fermentation of cotton stalk hydrolysate by Enterobacter cloacae WL1318 and construction of fhIA gene prokaryotic expression vector. Mater Dissertation of Tarim University. 2018. (in Chinese)

37. Jenni JS, Antti L, Tommi A, Olli Y, Matti TK, Ville S. Prospecting hydrogen production of Escherichia coli by metabolic network modeling. Int J Hydrogen Energy. 2013; 38(27): 11780-11789.

38. Jung MY, Ng CY, Song H, Lee J, Oh MK. Deletion of lactate dehydrogenase in Enterobacter aerogenes to enhance 2,3-butanediol production. Appl Microbiol Biotechnol. 2012; 95: 461-469.

39. Zhang Q, Li Y, Li J, Ma CM. Dilute acid hydrolysis of cotton stalks and ethanol production from hydrolytic liquids. Proceedings 2011 International Conference on Materials for Renewable Energy \& Environment (ICMREE 2011). 2011; 1: 459-

40. Li YB, Zhang Q, Deng L, Liu Z, Jiang H, Wang F. Biohydrogen production from fermentation of cotton stalk hydrolysate by Klebsiella WL1316 newly isolated from wild carp (Cyprinus carpio L.) of the Tarim River basin. Appl Microbiol Biotchnol. 2018; 102: 4231-4242.

41. van Soest PJ, Robertson JB, Lewis BA. Methods for dietary fiber, neutral detergent fiber, and nonstarch polysaccharides in relation to animal nutrition. J Dairy Sci. 1991; 74: 3583-3597.

42. Zhang K, Ren NQ, Cao GL, Wang AJ. Biohydrogen production behavior of moderately thermophile Thermoanaerobacterium thermosaccharolyticum W16 under different gas-phase conditions. Int J Hydrogen Energy. 2011; 36: 14041-14048.

\section{Tables}

Table 1 Parameters and correlation coefficients of the Gompertz model dynamically fitted cumulative hydrogen production for wild and recombinant strains 


\begin{tabular}{ccccc}
\hline Strains & \multicolumn{4}{c}{ Dynamically fitted parameters } \\
\cline { 2 - 5 } & $R_{m}\left(\mathrm{~mL} \mathrm{~L}^{-1} \mathrm{~h}^{-1}\right)$ & $P\left(\mathrm{~mL} \mathrm{~L}^{-1}\right)$ & $\lambda(\mathrm{h})$ & $R^{2}$ \\
\hline wild strain & 12.28 & 1078.33 & 12.82 & 0.9933 \\
recombinant strain & 22.42 & 1709.00 & 2.91 & 0.9826 \\
\hline
\end{tabular}

Table 2 The reducing sugar consumption, increment in $\mathrm{OD}_{600}$, bacterial growth efficiency, and hydrogen yield in the wild and recombinant strains

\begin{tabular}{|c|c|c|c|c|}
\hline \multirow[t]{2}{*}{ Strains } & \multicolumn{2}{|c|}{ Reducing sugar consumption } & \multirow{2}{*}{$\begin{array}{l}\text { Increment of } \mathrm{OD}_{600} \\
\left(\Delta \mathrm{OD}_{600}\right)\end{array}$} & \multirow{2}{*}{$\begin{array}{c}\mathrm{Y}\left(\mathrm{H}_{2} / \mathrm{S}\right) \\
\text { (mol } \mathrm{H}_{2} / \mathrm{mol} \text { sugar) }\end{array}$} \\
\hline & Glucose consumption (\%) & Xylose consumption (\%) & & \\
\hline wild strain & $74.22 \pm 0.27$ & $89.01 \pm 1.32$ & $2.63 \pm 0.01$ & $0.27 \pm 0.01$ \\
\hline recombinant strain & $83.12 \pm 1.21$ & $92.03 \pm 0.31$ & $2.67 \pm 0.03$ & $0.37 \pm 0.01$ \\
\hline
\end{tabular}

Table 3 Strains and plasmids used in this study

\begin{tabular}{|c|c|c|}
\hline Strain or plasmid & Genotype and relevant characteristics & $\begin{array}{l}\text { Reference or } \\
\text { source }\end{array}$ \\
\hline E. coli DH5 $\alpha$ & $\begin{array}{l}\text { F-, } \varphi \text { 80dlacZ } \Delta \text { M15, } \Delta \text { (lacZYA -argF) U169, deoR, recA1, endA1, hsdR17 }\left(\mathrm{rK}^{-}, \mathrm{mK}^{+}\right), \text {phoA, } \\
\text { supE44, } \lambda^{-} \text {, thi-1, gyrA96, relA1 }\end{array}$ & Sangon \\
\hline $\begin{array}{l}\text { E. } \\
\text { cloacae WL1318 }\end{array}$ & Wild type & [26] \\
\hline $\begin{array}{l}\text { E. } \\
\text { cloacae WL1318 - } \\
\text { fhlA }\end{array}$ & E. cloacae WL1318 containing pET28a-fhlA & This study \\
\hline pUCm-T & TA Cloning vector, $\mathrm{Amp}^{\mathrm{r}}$ & Sangon \\
\hline pET28a & Prokaryotic expression vector, $\operatorname{Kan}^{\mathrm{r}}$ & Miaolingbio \\
\hline pET28a-fhlA & fhlA in EcoR I-Xho I sites of pET28a & This study \\
\hline
\end{tabular}

Table 4 Primers designed for cloning and overexpression of the fhlA gene

\begin{tabular}{lll}
\hline Primers & Sequence & Source \\
\hline fhlA-fw & ATGAGCGATCTTGGACAGCAG & This study \\
fhlA-rv & TTAATTCAGGCTCTCTTATCA & This study \\
PfhlA-fw & ATGAATTCGAGCGATCTTGGACAGCAG & This study \\
PfhlA-rv & CGGCTCGAGTTAATTCAGGCTCTCTTTATCA & This study \\
\hline
\end{tabular}

\section{Figures}




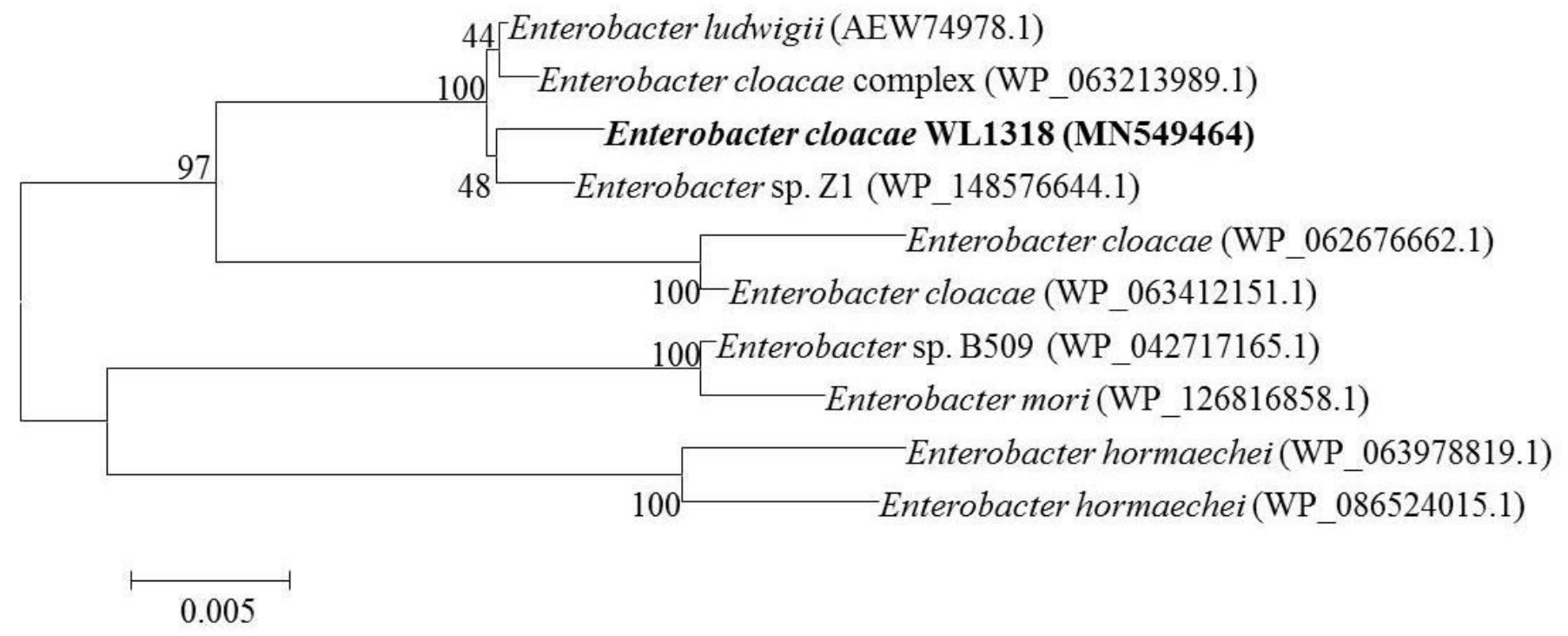

\section{Figure 1}

Phylogenetic tree of the formate hydrogen lyase transcriptional activator (FHLA) sequences. The tree was constructed using the neighbor-joining algorithm of the Mega 6.0 program with 1,000 bootstrap replicates. The GenBank accession numbers and strain name are indicated for each protein 


\section{$\mathrm{kDa} \quad \mathrm{WT} \quad \mathrm{RT}$}

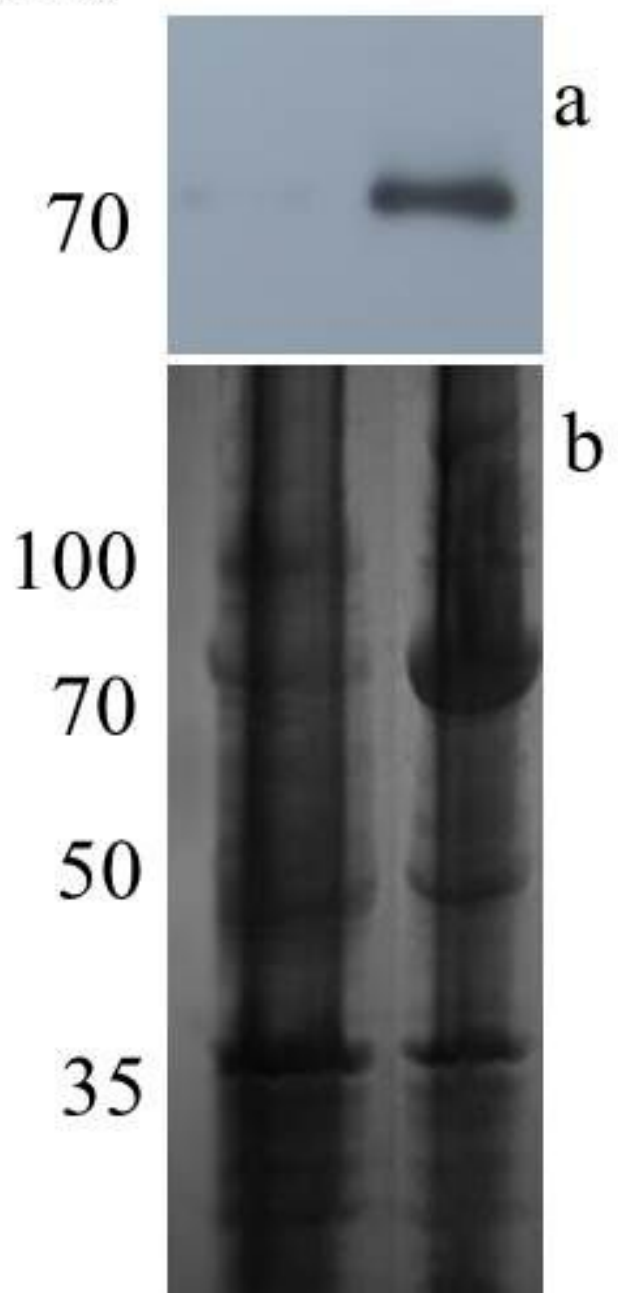

Figure 2

Expression of the fhIA gene in E. cloacae WL1318. A: Western blot analysis of the expression of the fhlA-encoded protein (upper panel). B: SDS-PAGE gel was stained with Coomassie Brilliant Blue (lower panel). WT: wild-type strain, RT: the recombinant strain; the numbers denote molecular masses in $\mathrm{kDa}$ 


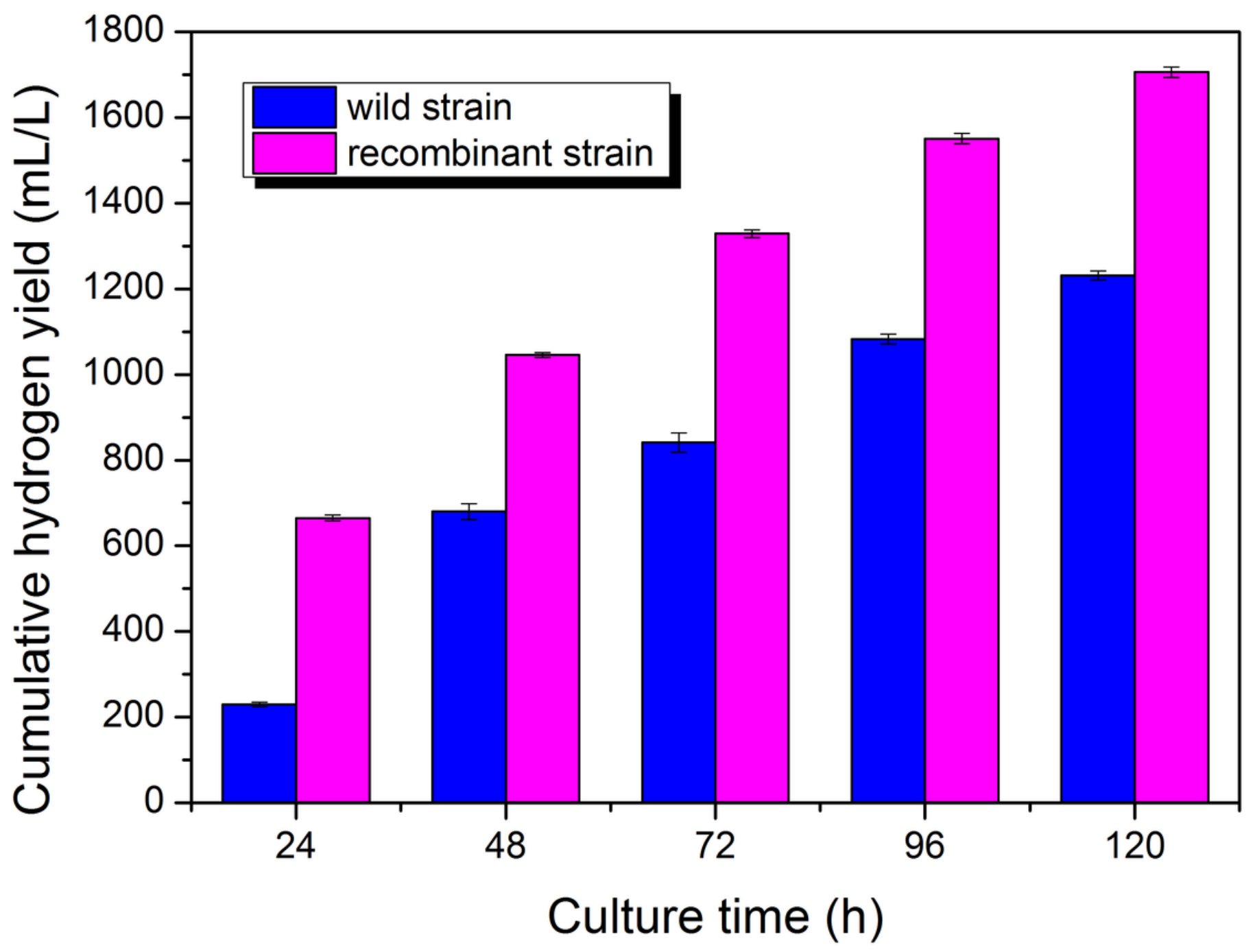

Figure 3

Time course profiles of cumulative hydrogen production for wild and recombinant strainsTime course profiles of cumulative hydrogen production for wild and recombinant strains 


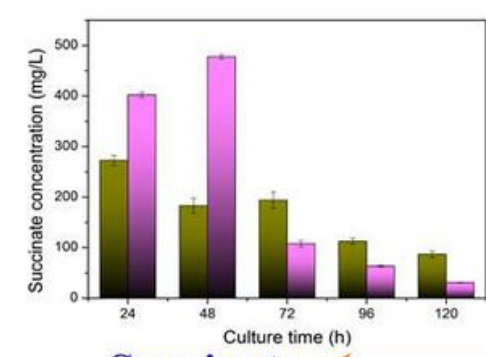

Succinate

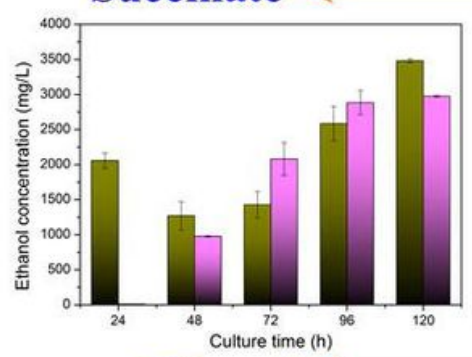

Ethanol

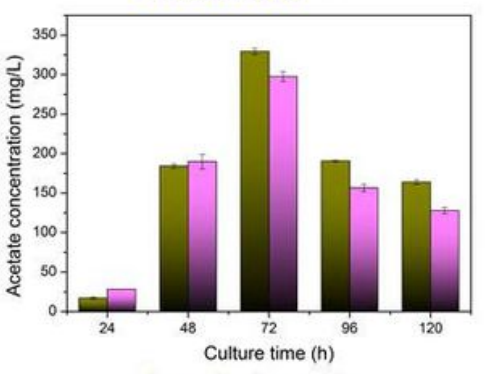

Acetate

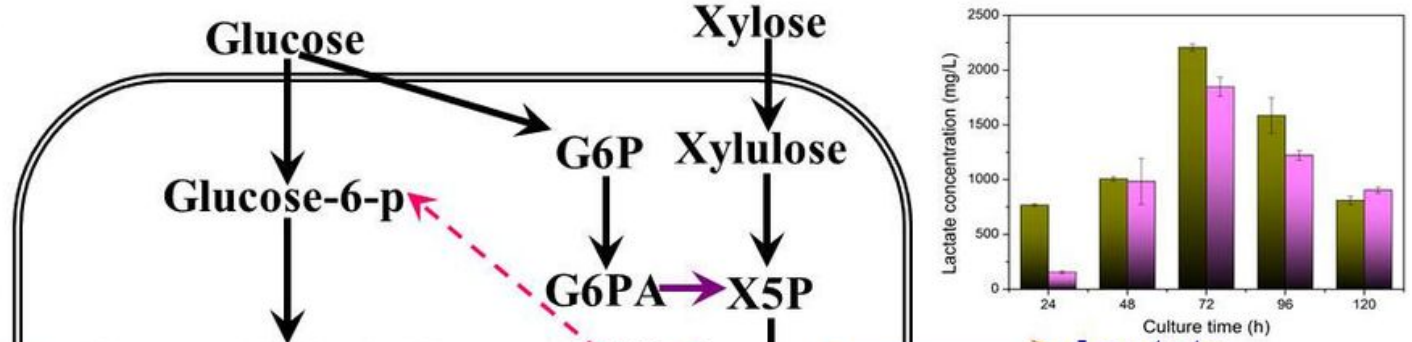

Lactate

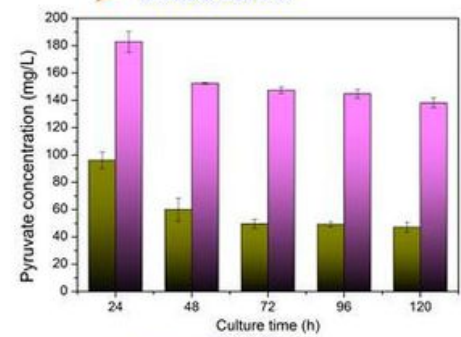

-Phosphoenolpyruvate

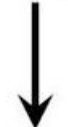

Pyruvate

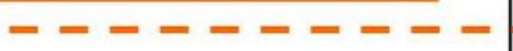

$-\rightarrow$ Pyruvate

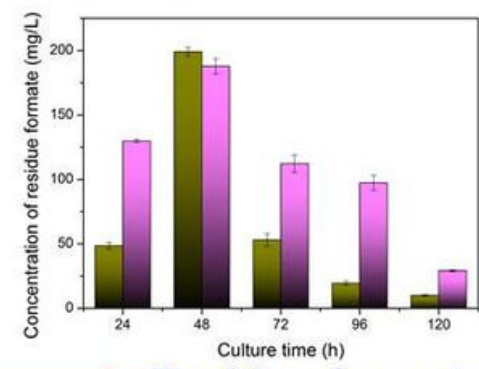

Residue formate

Figure 4

Metabolite profiles of the wild type and recombinant strains reflecting in the hydrogen production metabolic pathway during the entire fermentation stage. G6P: glucose-6-phosphate; G6PA: glucose-6phosphate acid; X5P: xylulose 5-phosphate; G3P: 3-phosphoglyceric acid
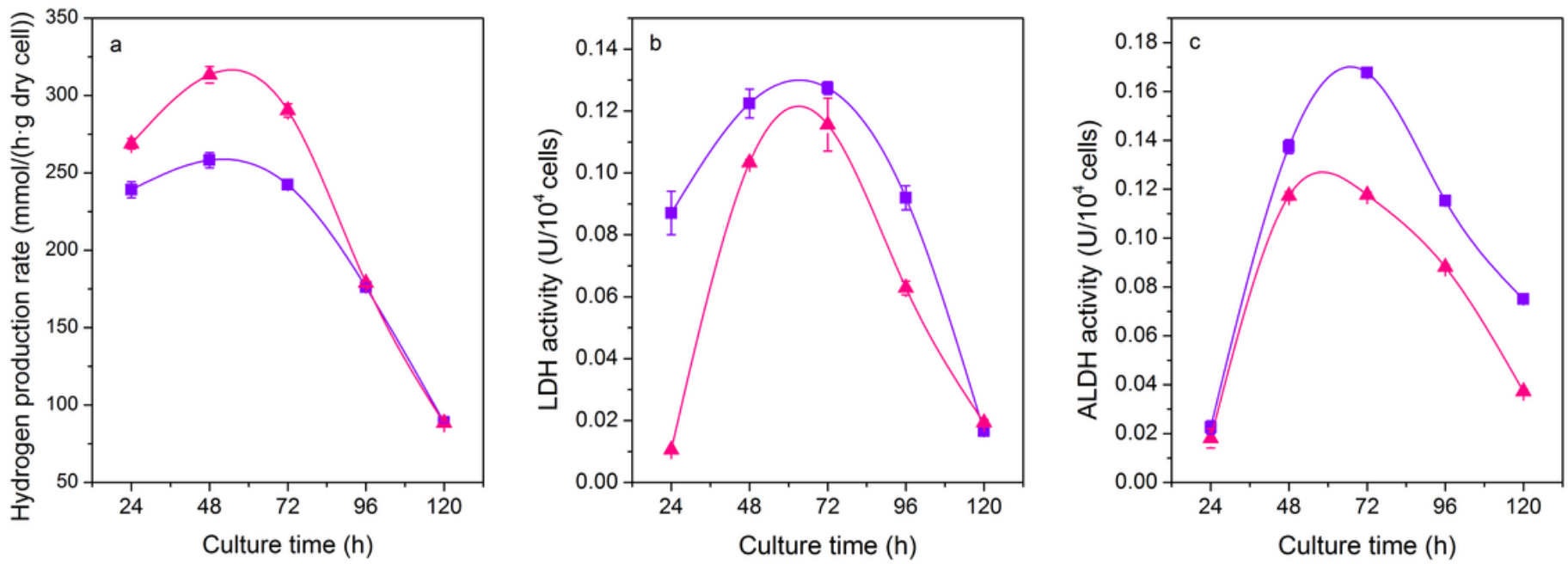
Figure 5

The specific enzyme activity of the wild and recombinant strains

\section{Supplementary Files}

This is a list of supplementary files associated with this preprint. Click to download.

- Additionalfile.docx 